Kompass

Dermatologie

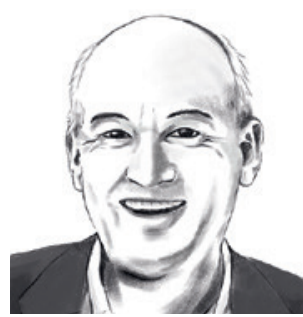

Harald Walach

Poznan/Berlin

Polen/Deutschland

«Der Versuch, den Tod mit allen Mitteln zu vermeiden ist die sicherste Art, ihn herbeizuführen.» Der Satz könnte von Karl Kraus oder Helmut Qualtinger sein. Ist er aber von mir (genauer gesagt aus dem Neuen Testament und von mir abgewandelt). Der Satz spricht eine Dialektik an, die heutzutage unmodern geworden ist: Gerade der Versuch, etwas zu verhindern, oder mit allen Mitteln zu erreichen, führt nicht selten zum direkten Gegenteil.

Wir sollten lernen, finde ich, mit dieser perfiden Dialektik zu leben: Wenn wir alles, vor allem im Gesundheitsbereich, tun, um ja keinen Gefahren, ja keinen Risiken, ja keinen Erregern ausgesetzt zu sein, dann ist das Ergebnis nicht sorgenfreies, glückliches Leben, «menschliches Erblühen - human flourishing», wie es Vertreter einer technokratischen Weltsicht erträumen [1, 2], sondern der garantierte Tod durch Langeweile, Bewegungsmangel und Herzinfarkt als Folge des Selbstschrecks.

Selbstschreck haben wir als Kinder öfter gespielt. Es geht so: Man fährt sich selbst mit einer Hand von hinten ganz, ganz langsam über den Hinterkopf, von unten nach oben, bis man ein leichtes Gruseln verspürt, und nimmt die letzten Zentimeter vom Scheitel bis zum Gesicht ganz schnell, am besten mit einem lauten «Huch!!» untermalt. Wenn man sich dabei nicht selbst zu Tode schreckt, dann mindestens die, die dabeistehen. Garantiert. Probieren Sie's mal! Der Punkt beim Selbstschreck ist: es gibt eigentlich keinen ernsthaften Grund sich zu ängstigen, aber der jagt uns einen Schrecken ein, als wäre der Leibhaftige selbst vor der Tür. Mit ausreichendem medialen Getöse kann alles zu einem Selbstschreck aufgebauscht werden. Eine Weile lang war es das Fett, vor allem das Cholesterin. So dass man schon beim Anblick von Eiern und Bratwürsten einen konditionierten Brechreiz bekommen konnte. Dann Zucker, Milch, Alkohol, Salz, Erdnüsse, Salzletten, Chips, Currywurst, Viren und Bakterien al-

\title{
Präventionsfalle und Selbstschreck
}

ler Art, Risikosportarten, Autofahren, oder noch schlimmer, Radfahren: Es gibt fast nichts, was nicht schon als Killer Nummer eins, zwei oder drei gebrandmarkt wurde und was man unbedingt vermeiden müsse, wenn man ein glückliches, langes, sinnerfülltes und vor allem gesundes und risikoarmes Leben führen will. Wenn man sich solchen Informationen ausreichend langsam und lange- siehe Selbstschreck - aussetzt und mit Inbrunst wiederholt, dann vermeidet man alles, was potenziell gefährlich sein könnte. Ohne Desinfektionsmittel auf keinen Fall mehr aus dem Haus; ohne Gesichtsmaske schon gar nicht. Oder am besten gar nicht mehr aus dem Haus gehen und die Nachbarin oder die Caritas um den Einkauf bitten, oder online shoppen und einen Entrümpelungsdienst mit dem wöchentlichen Abholen der Pizza- und anderer Schachteln betrauen. Und keinesfalls mehr vom Fernsehsessel aufstehen, denn man könnte ja die Ankündigung der nächsten Katastrophe im Fernsehen verpassen. Arbeiten am besten nur noch hinter dem Bildschirm und Kontakte allenfalls online pflegen. Urlaub? Zu gefährlich, wenn man sich die Risikostatistiken ansieht, wer da alles mit Flugzeug, Auto, Fahrrad, Gondelbahn, Bootsfähre, Segelboot, beim Wandern vom Wolf gerissen oder beim Schwimmen im Mittelmeer vom Hai oder im Atlantik von einer Strömung verschluckt ums Leben kam. Da komme ich doch lieber nicht ums Leben und bleib, wo ich bin.

Also ist doch die logische Lösung: Möglichst alles vermeiden. Zuhause bleiben. Nichts mehr tun. Vor allem nichts mehr, was Spaß macht und gefährlich sein könnte. Und der Tod durch acedia progressiva et idiopathica, vulgo: grassierenden, unerklärlichen Überdruss, ist sicher. Ich will damit nicht in Zweifel ziehen, dass Menschen bei Autorasereien ums Leben kommen, bei riskanten Mountainbike-Touren querschnittsgelähmt werden, sich mit Schnaps um ihren Verstand und ihr Leben saufen, von riskant aufgestellten Leitern zu Tode stürzen, ja, und dass manche wirklich auch an idiopathischer Cholesterinämie leiden und damit einen Herzinfarkt beschleunigen können und daher besser keine Bratwürste essen sollten, oder an einer bakteriellen oder viralen Sepsis versterben. Aber wie so oft auch hier: Einzelfälle können keine allgemeinen Regeln begründen. Ich beobachte, wie wir gerade anhand einer vor allem für alte und schwache Menschen gefährlichen Infektionskrankheit die totale Prävention durchexerzieren. Ich frage mich, wie lange es noch dauern wird, bevor wir in einer Gesellschaft landen, in der die moralische Verpflichtung zum «bleiben Sie gesund» vor alles andere gestellt wird, eine Art Gesundheitsfaschismus, wie Julie Zeh inn in einem sehr lesenswerten Buch einmal dargestellt hat [3]. Und ich kann mich des Gefühls nicht erwehren, dass der Versuch, den Tod mit allen Mitteln zu vermeiden, die sicherste Art ist inn herbeizuführen. Nicht nur individuell, sondern auch gesamtgesellschaftlich. Vielleicht sollten daher gerade Ärztinnen und Mediziner besonders kritisch sein, wenn Politiker und Nichtfachleute zu allen möglichen Präventionskampagnen blasen?

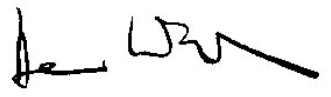

Prof. Dr. Dr. phil. Harald Walach

\section{Literatur}

1 Walach H: Schöne neue Welt? Ein Essay über Steven Pinker (2018) Enlightenment Now. Aufklärung und Kritik 2019;26:196-208.

2 Pinker S: Enlightenment Now: The Case for Reason, Science, Humanism, and Progress. London, Penguin, 2018.

3 Zeh J: Corpus Delicti: Ein Prozess. Schöffling, Frankfurt, 2009. 